Research Article

\title{
Analysis on Wetting Deformation Properties of Silty Clay
}

\author{
Xinrong Liu ${ }^{1}$, Dahe Qi * ${ }^{1}$, Yu Yu ${ }^{1}$ and Zhongping Yang ${ }^{2}$ \\ ${ }^{I}$ College of Civil Engineering, Chongqing University, Chongqing 400045, china \\ ${ }^{2}$ Department of Hydrology and Water Resources, The University of Arizona, Tucson, Arizona, USA
}

Received 3 March 2014; Accepted 20 July 2014

\begin{abstract}
Changes in water level that cause deformation and stability problems often occur in foundation pit engineering. Water damage is one of the main problems that will lead to disasters in foundation pit engineering. Research findings with regard to properties of wetting deformation due to water damage can be applied not only in foundation pit engineering, slope engineering, hydraulic engineering, and mining engineering but also in related issues in the field of theoretical research and practice. In this study, the characteristics of silty clay deformation after wetting are examined from the perspective of the effect of wetting on the side wall of foundation pit, and wetting experiments on silty clay of a selected area's stratum located in Chongqing Municipality are conducted under different confining pressures and stress levels through a multi-function triaxial apparatus. Then, laws of silty clay wetting deformation are obtained, and the relationship between wetting stress level and wetting deformation amount is also figured out. The study reveals that the maximum values of wetting deformation under different confining pressures have appear at a particular stress level; therefore, the related measures should be taken to avoid this deformation in the process of construction.
\end{abstract}

Keywords: Silty Clay, Wetting Deformation, Duncan - Chang Model

\section{Introduction}

With the rapid development of foundation pit engineering, foundation excavation accidents have frequently occurred in recent years, which have caused lots of great damage and loss in life. Most of the accidents were caused by water damage, which occurs when the rock mass around a foundation pit side wall deforms as a result of water soaking. This kind of deformation can evoke stress redistribution of rock and soil mass, then set off subsidence and fracture of the foundation pit side wall, which seriously undermines the safety of foundation pits and supporting structures.

The instability and the deformation caused by the water level changes are not just limited to the foundation pit engineering field. In China, heavy rains trigger landslides and mudslides in the mountainous region; melted spring snow triggers landslides at high altitudes; the reservoir water level drops abruptly to cause the dam slope instability; water mist is of great threat to the stability of rock slope; embankment collapse of large rivers are widespread; tailings dam accidents happen frequently. Although these problems do not belong to the category of foundation pit engineering, but the approaches to these problems and the conclusions have great significance for the study on underground water level changes caused by the instability and the deformation of foundation pit. Research findings with regard to properties of wetting deformation due to water damage can be applied not only in foundation pit engineering, slope engineering, hydraulic engineering, and mining engineering but also in related issues in the field of theoretical research and practice, so the study is of great significance in engineering field.

*E-mail address: zdyunzhiqi@163.com ISSN: 1791-2377 @ 2014 Kavala Institute of Technology. All rights reserved.
Silty clay is one of the most widely distributed clay soils in China Many. Scholars at home and abroad studied the silty clay such as K. H. Andersen [1] who discussed strength changes of clay and silty clay located in different areas after the circulating load in his papers. These studies on original state and restore Marine soft soil conclude that soils in different areas had distinct properties and their strengths also vary after vibration. And the study of D. C. Koutsoftas, Yasuhara K [2], [3], [4] proves that the strength of original soil attenuates to a large extent compared with the strength of the soil without the circulating load. The attenuation related to the properties of soil sample and the conditions of vibration, etc. is caused by the increase of sample's pore pressure and decrease of effective stress due to dynamic load. The research of G. Castro and G. T. Christian [5] showed that intensity of the soil after vibration had no significant changes while the experiment of G. Austin [6] showed that intensity of soil increase in a manner after vibration as the dynamic stress was less than a given value. However, the studies concerning silty clay deformation after immersion are still very few in academe.

A landmark project whose build-up area is $30751 \mathrm{~m}^{2}$ and maximum depth is $26 \mathrm{~m}$ on the waterfront of Jialing River located in Chongqing Municipality is chosen to study the foundation pit. The reason of choosing the foundation pit of the landmark project is that, the stratum of the foundation pit is the quaternary holocene alluvium $\left(Q_{4}^{a 1}\right)$ silty clay and its underground water has a direct hydraulic connection with the Jialing River. In this article, the concept of silty clay wetting deformation is introduced to examine the characteristics of deformation of silty clay after soaking. Wetting deformation was initially applied to coarse grained soil, some scholars advocated that the coarse grained soilafter soaking under a certain stress could generate slip, 
break and rearrangement, which also could lead to external deformation and stress redistribution [7], [8]. This mechanism shows that deformation is not the subsidence as a result of changes in underground water level, but the deformation as a result of the soil from dry to wet at a constant stress state [9]. This study is based on previous researches [10], [11] and uses some standards[12] to conduct triaxial wetting tests on silty clay strata under different confining pressures and different stress levels to explore the law of silty clay wetting deformation.

\section{Triaxial wetting test}

\subsection{Sample introduction}

The sample for testing is quaternary holocene alluvium silty clay collected from the Jialing river bed, whose depth is 6.0 $\mathrm{m}$. The original soil is dug from $200 \times 200 \times 200 \mathrm{~mm}^{3}$ cubes at the excavation site. Firstly, it's up and down sides are labelled; secondly, it is wrapped by plastic paper and packing tape; thirdly, it is put into an iron box with its lid sealed; and finally the shock absorption measures is taken to reduce its disturbance in transit. The soil sample is taken to the laboratory and analyzed in accordance with test procedures. Special cut earthenware is used to make cylindrical samples with a height of $80 \mathrm{~mm}$ and a diameter of $39.1 \mathrm{~mm}$. Table 1 shows the physical properties of the sample (consolidated drained shear test).

\subsection{Triaxial wetting test procedure}

As to immersion saturation process, tests that compare the water saturation method with the back saturation method are conducted first.

Tab.1. Basic properties of sample

\begin{tabular}{|c|c|c|}
\hline $\begin{array}{c}\text { water content } \\
\%\end{array}$ & $\begin{array}{c}\text { natural density } \\
\mathrm{g} / \mathrm{cm}^{3}\end{array}$ & $\begin{array}{c}\text { saturated density } \\
\mathrm{g} / \mathrm{cm}^{3}\end{array}$ \\
\hline 22.14 & 1.98 & $\begin{array}{ll}2.14 & 1.58 \\
\end{array}$ \\
\hline void ratio & $\begin{array}{c}\text { cohesive force } \\
\mathrm{kPa}\end{array}$ & internal friction angle \\
\hline 0.724 & 18.12 & 22.01 \\
\hline
\end{tabular}

In the light of some previous studies [13], [14], a water head with one meter is selected to realize the water saturation method. The sample is immersed with air-free water from the bottom up. When the influent quantity is equal to the effluent quantity, the sample is completely saturated.

The back pressure saturation method involves in increasing the pore pressure (back pressure) to a certain extent so that the residual air in soil sample is dissolved by the water to achieve saturation. The confining pressure increases with the pore pressure (back pressure) on the increase, meanwhile an effective confining pressure in the soil sample should be maintained; then, according to the Skempton formula [15], the pore pressure $\operatorname{coefficient} B$ is calculated, $B=\Delta U / \Delta \sigma_{3}$, in which $\Delta \sigma_{3}$ is the confining pressure increment and $\Delta U$ is the pore pressure increment induced by the confining pressure rising.

In general, if the value $B$ is greater than or equal to 0.95 , the soil sample is considered saturated; if not, it is necessary to continuously boost the confining pressure and back pressure. If the value $B$ is less than 0.95 , the confining pressure and back pressure whose maximum pressure can run up to $600 \mathrm{kPa}$ [16] are increased by three times and the value $\mathrm{B}$ remains unchanged or even decreases, the soil sample is also considered saturated.
Table 2 shows the test results. The water saturation method has a saturation time of above $120 \mathrm{~h}$ (sample 1, 2, 3 and 4). The back pressure saturation time is $50 \mathrm{~h}$ to $70 \mathrm{~h}$ (sample 5 , 6, 7 and 8). After saturation, a sample is taken to determine its moisture content. The saturation ratio and moisture content are then compared. The saturation ratio of water saturation method is from $80 \%$ to $90 \%$, and the saturation ratio of back pressure saturation method is from $90 \%$ to $95 \%$. Therefore, in the following triaxial wetting tests, the back pressure method is used to make the soil sample fully saturated.

Tab. 2. Comparison of saturated time

\begin{tabular}{ccc}
\hline Sample number & $\begin{array}{c}\text { Saturation time } \\
\mathbf{~ h}\end{array}$ & $\begin{array}{c}\text { Saturation degree } \\
\mathbf{\%} \%\end{array}$ \\
\hline 1 & 125 & 82 \\
2 & 136 & 84 \\
3 & 132 & 80 \\
4 & 140 & 90 \\
5 & 58 & 90 \\
6 & 56 & 88 \\
7 & 60 & 95 \\
8 & 62 & 89 \\
\hline
\end{tabular}

The confining pressures of the test are $0.1 \mathrm{MPa}, 0.2 \mathrm{MPa}$ and $0.3 \mathrm{MPa}$ respectively. The soaking procedures are as follows: the sample of unsaturated natural soil is consolidated to be stable under certain confining pressures, then triaxial compression tests on the sample is carried out; when the axial stress reaches $1 / 3,1 / 2$, and $2 / 3$ of shear failure stress of unsaturated drainage consolidation respectively, or the stress level $\mathrm{S}$ gets to1/3,1/2, and $2 / 3$, axial shear stress can be ceased; as axial strain is less than $0.1 \%$ per hour, the sample is soaked into saturation from bottom to top, the soaking process is also called wetting process, the confining pressure $_{\sigma_{3}}$, and axial stress $\left(\sigma_{1}-\sigma_{3}\right)$ remains fairly constant during the whole process. When the sample is saturated and the axial strain is less than $0.1 \%$ per hour, the soaking procedure is done. The soaking deformation is the completed soaking deformation minus initial deformation. Furthermore, the sample is proceeded with triaxial compression test until their damage.

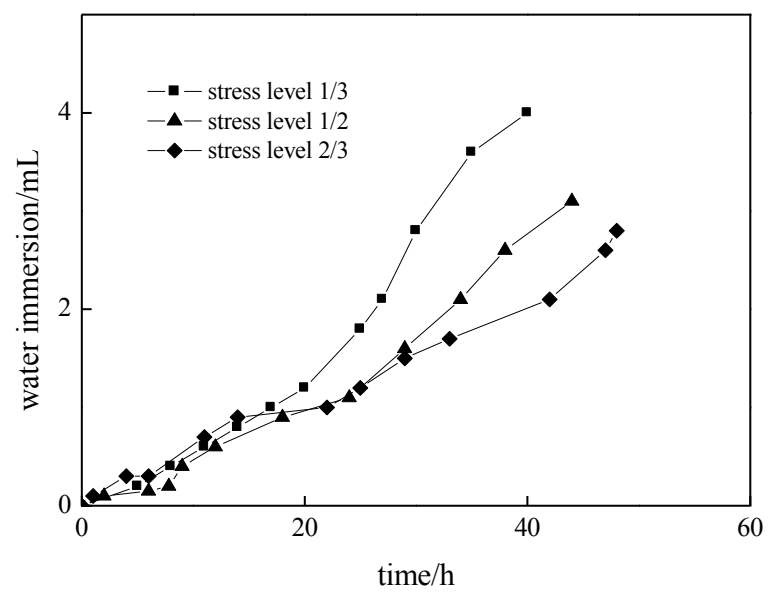

Fig.1. Water immersion curve over time under different $\mathrm{S}$ with $\sigma_{3}=100$ $\mathrm{kPa}$

Fig.1, Fig.2 and Fig.3 show that the quality of water changes as time goes on during the soaking process. The higher the confining pressure is, the shorter the soaking time is, the soaking time is reduced from 48 hours to 22 hours; 
then the total water immersion become smaller after the soaking process is over. Under the same confining pressure, the greater the stress level is, the longer saturation time is; surprisingly, the total water immersion becomes even smaller. The actual volume change of sample cannot be directly measured in the test, thus the change of water immersion reflects the change in the sample volume to some extent.

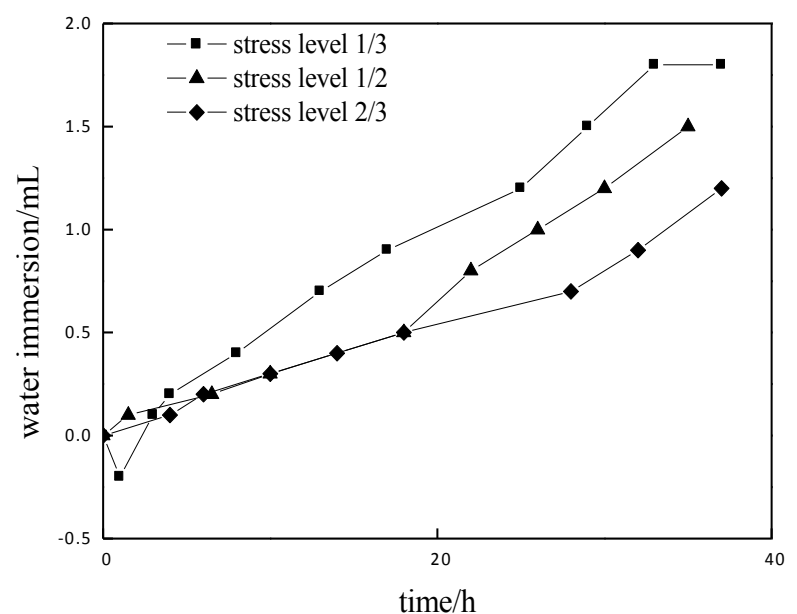

Fig.2. Water immersion curve over time under different $S$ with $\sigma_{3}=200$ $\mathrm{kPa}$

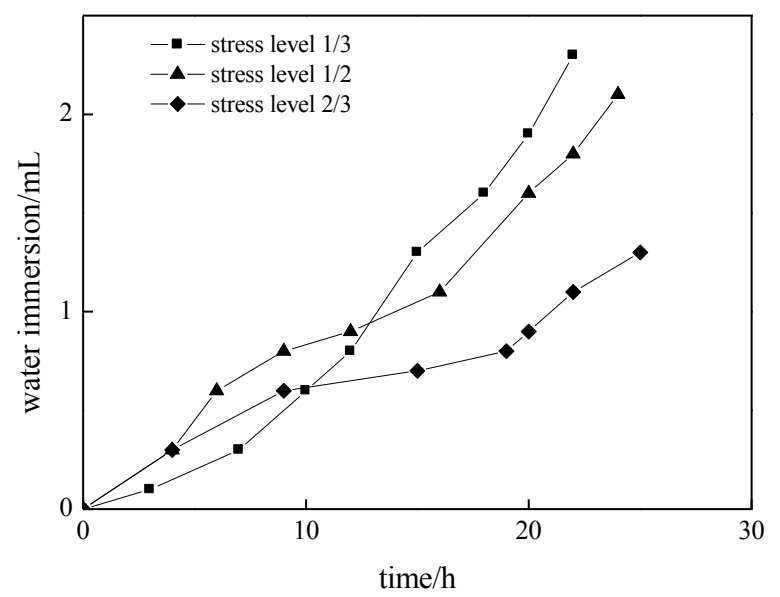

Fig.3. Water immersion curve over time under different $\mathrm{S}$ with $\sigma_{3}=300$ $\mathrm{kPa}$

\section{Results and analysis of wetting deformation}

\subsection{Discussion}

Duncan et al. [17] applied the classical triaxial compression test to obtain the $\left(\sigma_{1}-\sigma_{3}\right)-\varepsilon$ test curve, and found out the same mathematical formula to reflect the non-liner properties of soil. In 1963, Duncan and Kondner [18] recommended the use of the following hyperbola curve instead of the $\sigma_{d}-\varepsilon_{1}$ curve when $\sigma_{3}$ was a constant,

$$
\sigma_{d}=\sigma_{1}-\sigma_{3}=\frac{\varepsilon_{1}}{a+b \varepsilon_{1}}
$$

or $\varepsilon_{1}=\frac{a \sigma_{d}}{1-b \sigma_{d}}$

In the formula,

$\sigma_{1}$ represents major principal stress;

$\sigma_{3}$ represents least principal stress;

$a, b$ represent experiment constants; $a, b$ are the functions of $\sigma_{3}$.

When the strain becomes very small, the initial elastic modulus is $E_{i}$, shown as follow:

$$
E_{i}=\left(\frac{\sigma_{d}}{\varepsilon_{1}}\right)_{\varepsilon_{1} \rightarrow 0}=\frac{1}{a}
$$

$a$ is the reciprocal of the initial elastic modulus.

When the strain becomes very large, the limit value of stress (confined compressive strength) is shown as follow:

$$
\left(\sigma_{d}\right)_{u / t}=\left(\sigma_{d}\right)_{\varepsilon_{1} \rightarrow \infty}=\frac{1}{b}
$$

Formula (4) is the asymptote of the stress strain curve. The actual destruction stress-strain curve is confined to the compression strength $\left(\sigma_{d}\right)_{f}$. Generally, this curve cannot reach the limit value $\left(\sigma_{d}\right)_{u / t}$. The ratio between $\left(\sigma_{d}\right)_{f}$ and $\left(\sigma_{d}\right)_{u / t}$ is known as the damage ratio $R_{f}$,

$R_{f}=\frac{\left(\sigma_{d}\right)_{f}}{\left(\sigma_{d}\right)_{u / t}}=b\left(\sigma_{d}\right)_{f}$

or

$b=\frac{R_{f}}{\left(\sigma_{d}\right)_{f}}$

$R_{f}$ is generally between 0.75 and 1.0 . According to the test results, $R_{f}=0.85$. Therefore, Equation (1) can be presented as follow:

$\sigma_{d}=\frac{\varepsilon_{1}}{\frac{1}{E_{i}}+\frac{\varepsilon_{1}}{\left(\sigma_{d}\right)_{f}} R_{f}}$

Fig.4, Fig.5 and Fig.6 are stress-strain relation curves of three stress levels under different confining pressures of wetting test which are in line with the hyperbolic relation of Duncan - Chang model. The figures show the whole procedures of the soaking, namely stress relaxation arise at the beginning; and then the axial stress reduces while the strain remains a certain value during the process; finally, at the end of soaking, the axial stress remains more or less unchanged but strain slightly hits its lowest point. 
After coordinate transformation, $\varepsilon /\left(\sigma_{1}-\sigma_{3}\right)$ and $\varepsilon$ show a good linear relationship, as indicated in Fig.7, Fig.8 and Fig. 9. The findings conform to the Duncan-Chang model.

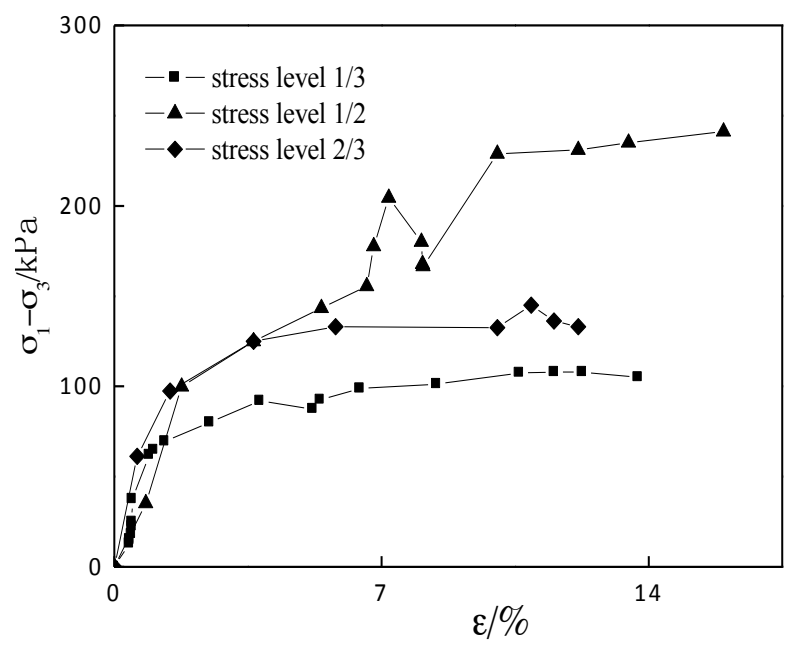

Fig.4 Curves of $\sigma_{1}$ and $\varepsilon$ under different $\mathrm{S}$ with $\sigma_{3}=100 \mathrm{kPa}$

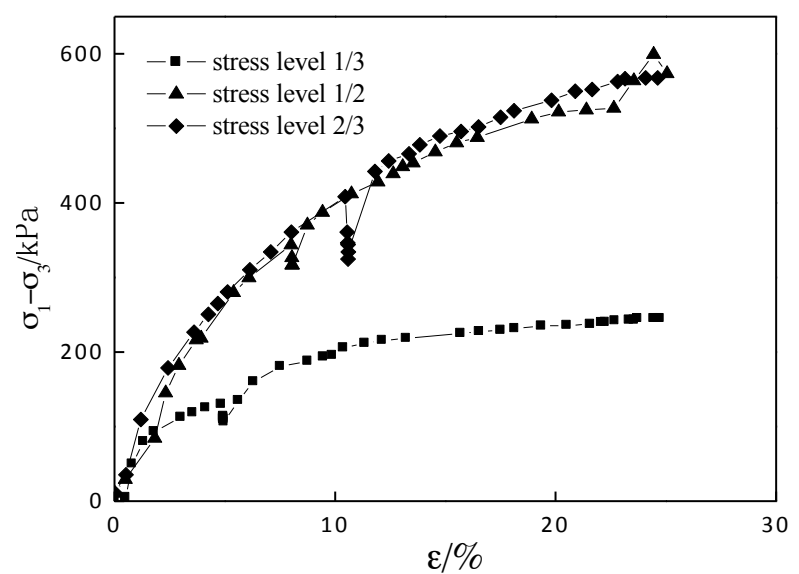

Fig.5. Curves of $\sigma_{1}$ and $\varepsilon$ under different $\mathrm{S}$ with $\sigma_{3}=200 \mathrm{kPa}$

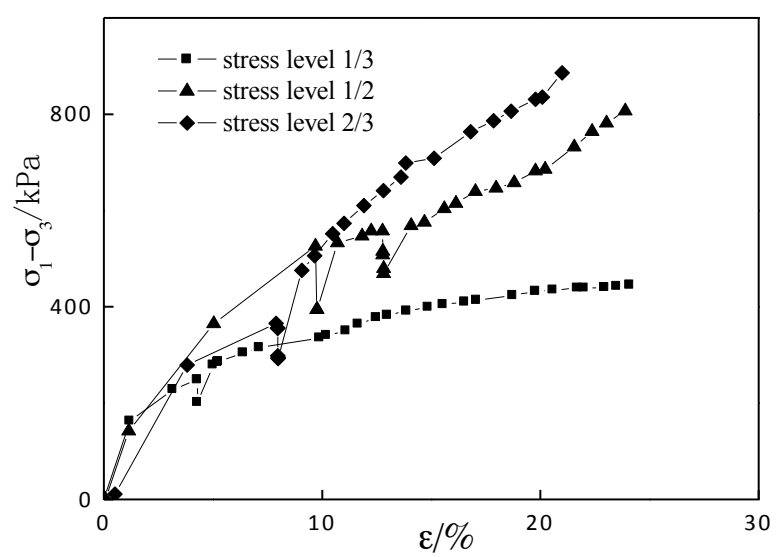

Fig.6. Curves of $\sigma_{1}$ and $\varepsilon$ under different $\mathrm{S}$ with $\sigma_{3}=200 \mathrm{kPa}$

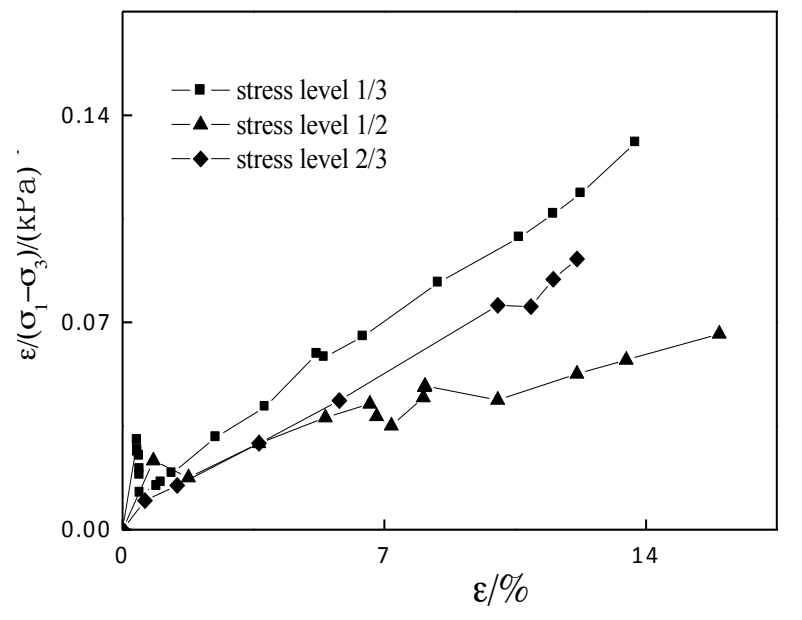

Fig.7. Curves of $\varepsilon / \sigma_{1}-\sigma_{3}$ and $\varepsilon$ with $\sigma_{3}=100 \mathrm{kPa}$

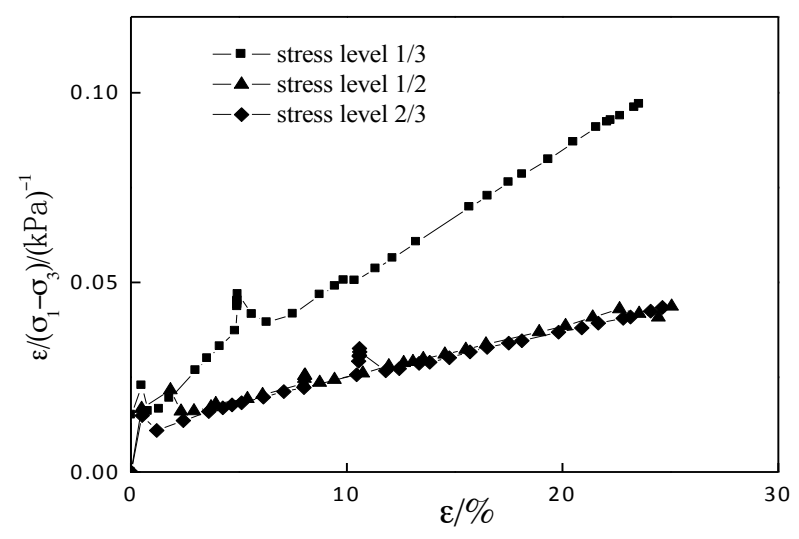

Fig.8. Curves of $\varepsilon / \sigma_{1}-\sigma_{3}$ and $\varepsilon$ with $\sigma_{3}=200 \mathrm{kPa}$

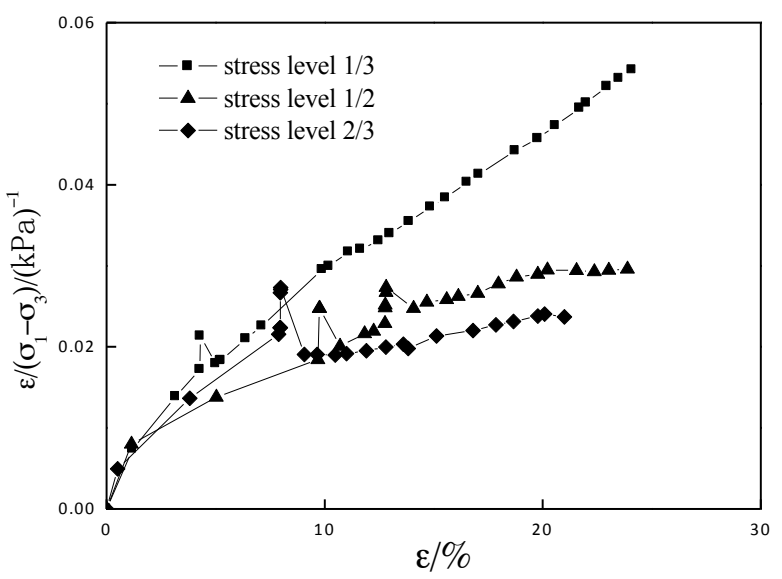

Fig.9. Curves of $\varepsilon / \sigma_{1}-\sigma_{3}$ and $\varepsilon$ with $\sigma_{3}=300 \mathrm{kPa}$

For geotechnical materials, when the stress - strain curves of triaxial compression test meet the hyperbolic relationship, the deformation parameters should be satisfied with the Janbu formula [19].

$$
E_{i}=K P_{a}\left(\frac{\sigma_{3}}{P_{a}}\right)^{n}
$$

In the formula, 
$P_{a}$ represents the atmospheric pressure;

$K$ represents the test constant for different soil types; $\mathrm{n}$ represents the test constant for different soil types; $K$ is the constant parameter that can be less than 100 or greater than 3,500 .

The data for this study are arranged in curves, as shown in Fig.10, however, deformation parameters cannot be arranged into a straight line. Thus, the curves of these parameters have no obvious law and cannot satisfy the Janbu formula.

The test parameters $1 / a$ and $\sigma_{3}$ are arranged, the following formula can be obtained and in Fig.11, 1/a and $\sigma_{3}$ show a good linear relationship, which is inconsistent with the law of coarse grained soil as well as soil compression deformation[20],[21],[22].

$\lg \left(\frac{1}{a}\right)=A+B \sigma_{3}$

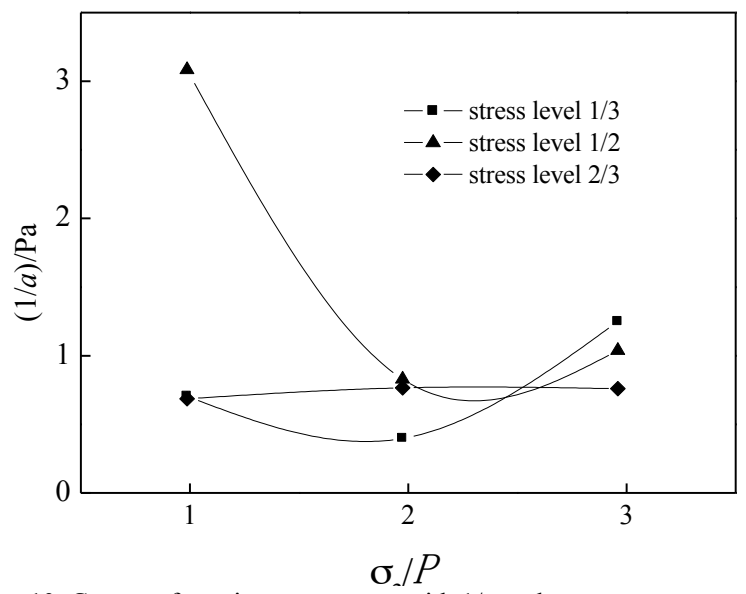

Fig. 10. Curves of wetting parameters with $1 / a$ and $\sigma_{3}$

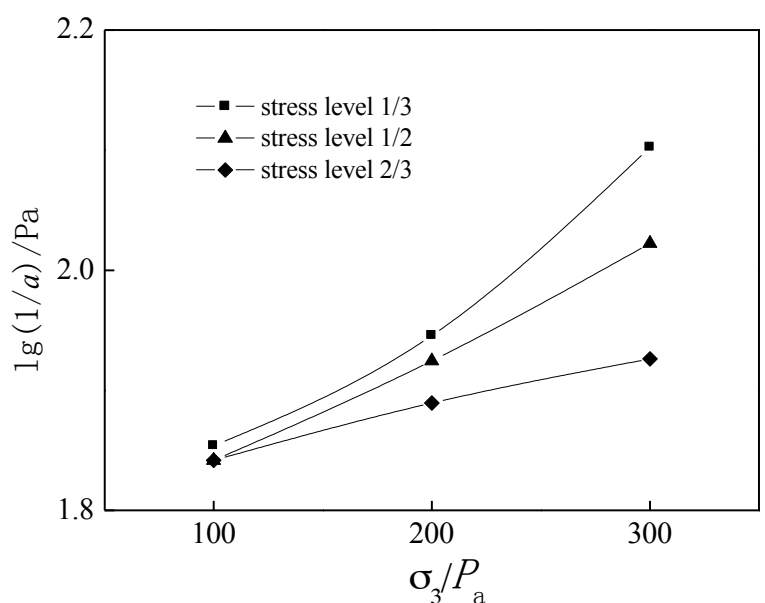

Fig.11. Curves of wetting parameters with $1 / a$ and $\sigma_{3}$

\subsection{Laws of stress level and axial deformation}

Fig.12 and Fig.13 show that under the same confining pressure, the axial strain increases with the stress level. However, the volumetric strain decreases after the stress level gains peak value. When the humidity level $\mathrm{S}=0.34$, the volume change maximizes at about $4.5 \%$. That's the reason why dewatering and water-blocking measures should be taken in the process of construction.

Wetting axial strain under low confining pressure is smaller than that under high confining pressure. When the confining pressure increases, the wetting deformation has a tendency to stability.

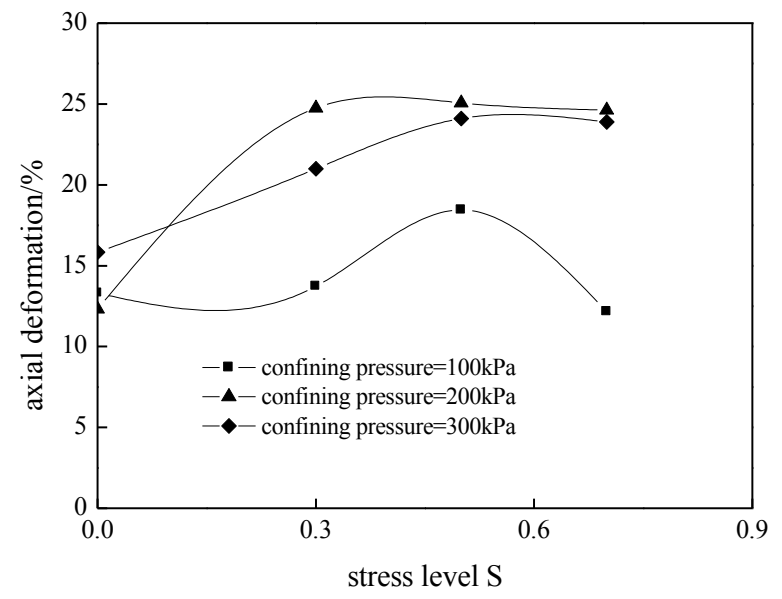

Fig. 12. Curves of the stress level and the axial deformation under different confining pressures

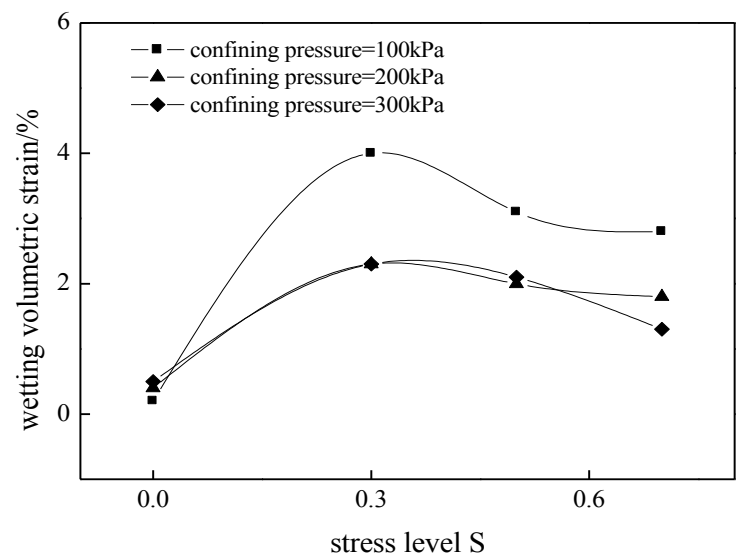

Fig. 13. Curves of the stress level and the volumetric strain under different confining pressures

\section{Conclusions}

This paper introduces the concept concerning wetting deformation of coarse grained soil to study the silty clay located in Chongqing. A series of triaxial tests are conducted: firstly, the original undisturbed silty clay sample is put onto the triaxial test machine; and then axial pressure is applied to gain different stress level under different confining pressure; finally, the sample is immersed to saturation for the sake of exploring the law of the silty clay with regard to wetting deformation. The conclusions are as follows:

(1)The stress-strain relationship of wetting process is broadly in line with the hyperbolic relation of the DuncanChang model, but the model's parameters $1 / a$ and $\sigma_{3}$ do not completely conform to the Janbu formula. In addition, $\log (1 / a)$ and $\sigma_{3}$ show a good linear relationship. 
(2)When the wetting stress level is approximate to 0.34 and the wetting volumetric strain variables reach the largest, measures should be taken to avoid the water damage.

(3)The water immersion decreases as the confining pressure increases. The change of water immersion reflects the change of the sample volume to some extent.

(4)The changes of wetting axial strain is smaller at lower confining pressure than that at higher confining pressure, the wetting deformation has a tendency to stability when the confining pressure increases.

The experimental study in this paper analyzes the characteristics about the wetting deformation of silty clay. The research results have significance in deep foundation pit engineering construction; the measures should be adopted during the construction to block the underground water from soaking into the foundation pit side wall soil, which can avoid the occurrence of wet deformation for the benefit of the supporting structure. This study is also valuable for applications in the slope engineering, hydraulic engineering, mining engineering and related field.

\section{Acknowledgements}

This study was supported by fund project as follows: The Specialized Research Fund for the Doctoral Program of Higher Education of China (20110191120033), The Fundamental Research Funds for the Central Universities (Project No. CDJZR1220 0018).

\section{References}

1. K H Andersen, W F Rosenbrand, S F Brown, et al, "Cyclic and static laboratory tests on Drammen clay", Journal of the Geotechnical Engineering, 106(5), 1980, pp. 499-529.

2. D C Koutsoftas, "Effect of cyclic loads on undrained strength of two marine clays", Journal of the Geotechnical Engineering Division, 104(5), 1978, pp.609-620.

3. Yasuhara K, Murakami S, Song B W, et al, "Post cyclic degradation of strength and stiffness for low plasticity silt", Journal of Geotechnical and Geoenvironmental Engineering, 129(8), 2003, pp.756-769.

4. Yasuhara K, "Post cyclic undrained strength for cohesive soils", Journal of the Geotechnical Engineering Division, 120(11), 1994, pp.1961-1979.

5. G Castro, J T Christian, "Shear strength of soils and cyclic loading", Journal of the Geotechnical Engineering Division, 102(9) 1976, pp. 887-894.

6. G Austin, "The behaviour of Keuper Marl under undrained creep and repeated loading", [Ph.D.thesis], Nottingham: University of Nottingham, 1979.

7. Yin Z-Z, Fei Y-Q, Zhang J-F, "Experimental study of wetting deformation of filling soil at xiaolangdi dam", Advances in Science of Hohai, 14(4), 1993, pp.73-76. (in Chinese)

8. Qian J-H, Yin Z-Z, "Theory and Calculation Soil Engineering", China Water Power Press, Beijing, China, 1990, pp.181-185. (in Chinese)

9. Li G-X, "Slacking test and math model of rock fill", Chinese Journal of Geotechnical Engineering, 21(05), 1990, PP. 58-64. (in Chinese)

10. Wei S, "Study on wetting deformation behaviour and numerical model of coarse-grained materials", [Ph.D.thesis], Hohai University, Nanjing, China, 2006, pp.15-23. (in Chinese)

11. Li P, Li Z, Liu J-Y, "Slaking test study of coarse aggregate under high triaxial stress condition". Chinese Journal of Rock Mechanics and Engineering, 23(2), 2004, PP.231-234. (in Chinese)
12. Editorial industry standard of the People's Republic of China, The Professional Standards Compilation Group of People's Republic of China, Specification of Soil Test, SL237-1999. (in Chinese)

13. Ordemir I, Oezkan, Y, "Compression of alluvial deposits due to wetting", Proceeding of the International Conference on Soil Mechanics and Foundation Engineering, AA Balkema: San Francisco, 1985, pp.12-16.

14. Bao H-F, Qu Z-J, "The study of wetting properties for coarse materials". Journal of Chengdu University of Science and Technology, 43(1), 1989, pp. 23-30. (in Chinese)

15. Skempton, A.W, Northey, R.D., "Sensitivity of Clays", Geotechnique, 3(1), 1952, pp. 40-51.

16. American Society for Testing and Materials. e.d. Annual book of ASTM standards, Soil and rock (1). 2012.

17. Duncan J M, Chang C Y, "Nonlinear Analysis of Stress and strain in soil”, Journal of Geotechnical Engineering, 96(SMS), 1970, pp. 89-94.

18. Konder R L, "Hyperbolic Stress Strain Response: Cohesive Soils", Journal of the Soil Mechanics and Foundations Division, 89(SM1), 1963.

19. Duncan J M, P Byrne, K.S, Wong, P. Mabry, "Strength stressstrain and Bulk modulus Parameters for Finite Element Analyses of Stresses and movement in soil masses", Report No. UCE/GT/80-01, 1980.

20. Guo Q-G, "Engineering Characteristic and Application of Coarse Grained Soil". Yellow River Water Conservancy Press, Zhengzhou, China, 1998, pp.135-142. (in Chinese)

21. Zhang S-H, Zhang A-J, Chen T, "Triaxial slaking test research on rock fill deformation feature". Chinese Journal of Rock Mechanics and Engineering, 24(2), 2005, pp.5938-5942. (in Chinese)

22. Zhu B-L, Shen Z-J, Gong X-N, "Computational Soil Mechanics", Shanghai Science and Technology Press, Shanghai, China, 1990. (in Chinese) 